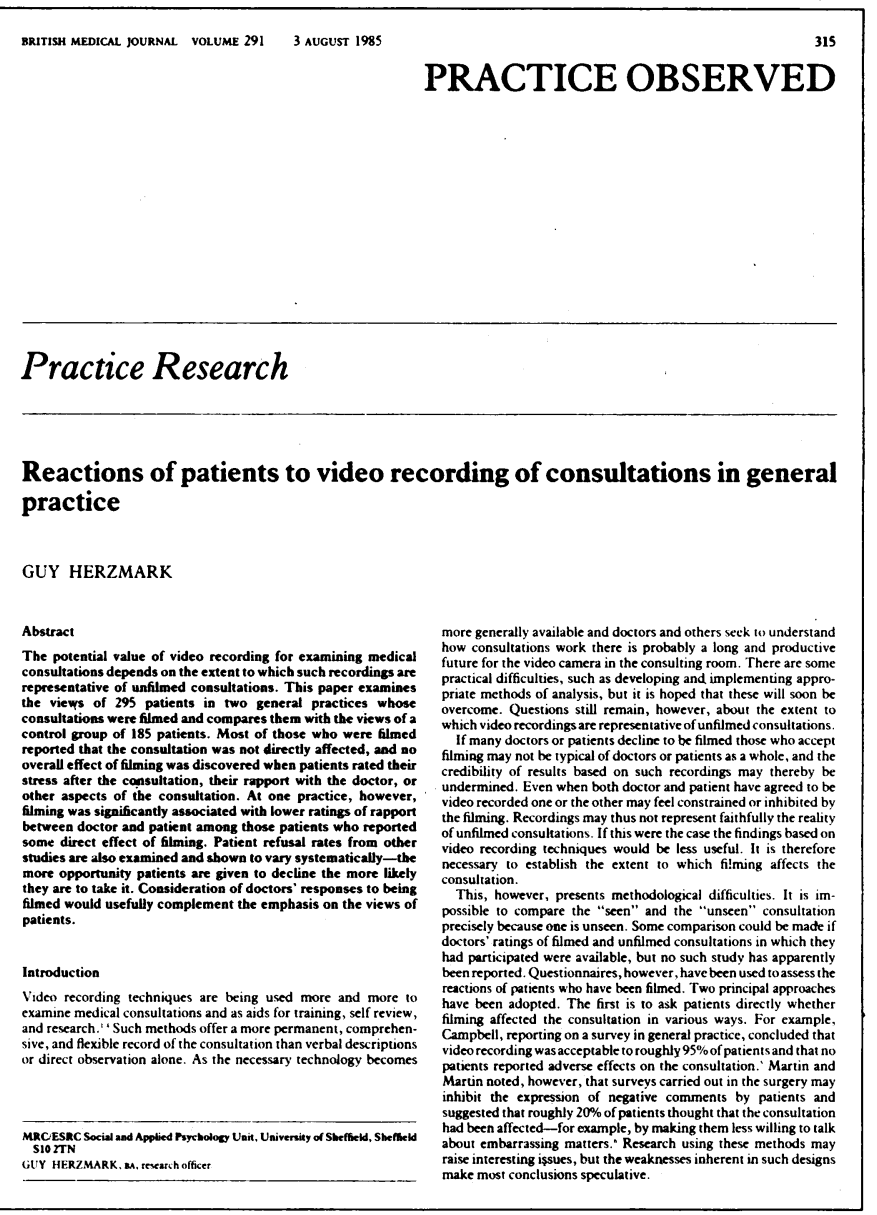
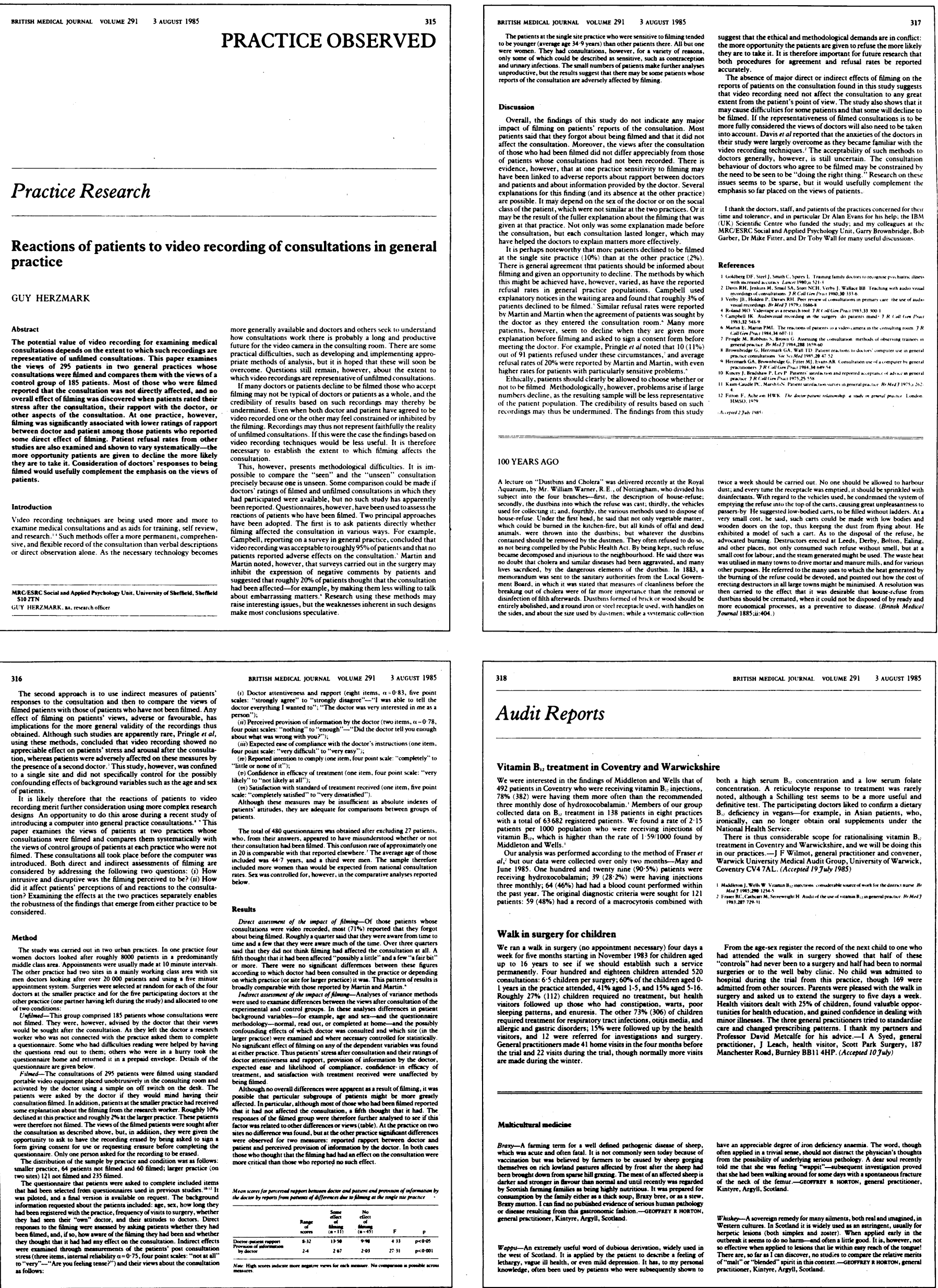

318

\section{Audit Reports}

Vitamin $B_{12}$ treatment in Coventry and Warwickshire

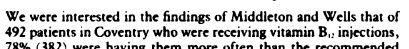

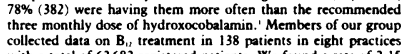

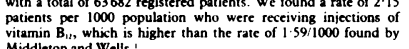
Our analysis was performed according to the method of Fraser et
at; but our data werc collected over only two months--May and
Junee

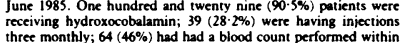

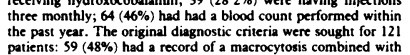

BRTTISH MEDICAL JOURNAL VOLUME 2913 A AUGUST 198

\section{Walk in surgery for children}

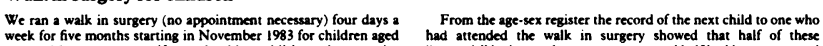

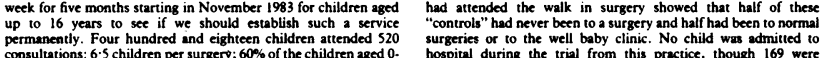

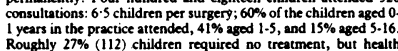
Roughly $27 \%$ (1112) children required no treactent, but health
visiors followed up chose who had constipation, wars, poor
steeping patterns, and enuresis. The other $73 \%$ (306) of children

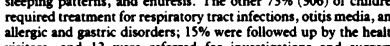

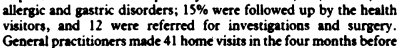
General praccitioners made 1 home visits in the four months before
the riial and 22 visists during the trial, though normally more visits
are made during the winter.

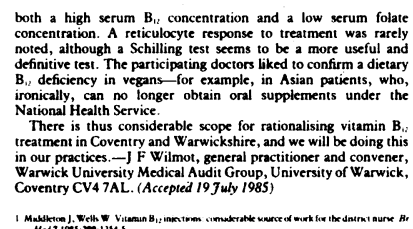

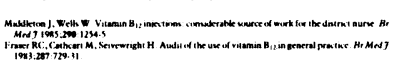

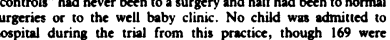
hospital during the trial from this practice, though 169 wer surgery and asked sus to extend the surgery to five days a week.
Health visitors dealt with $25 \%$ of children, found valustoc oppor.

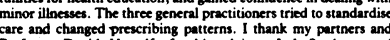

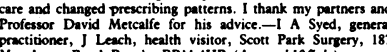

Multicuttural mediciere

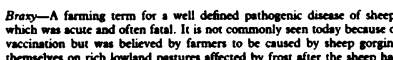

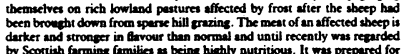

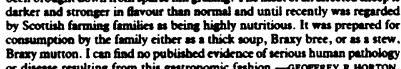

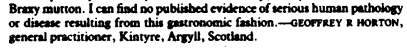

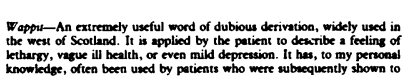

